\title{
Carlos Salvador Alvarado (1955-2021): A Man for All Eras
}

\author{
Etzel Cardeña' \\ Lund University
}

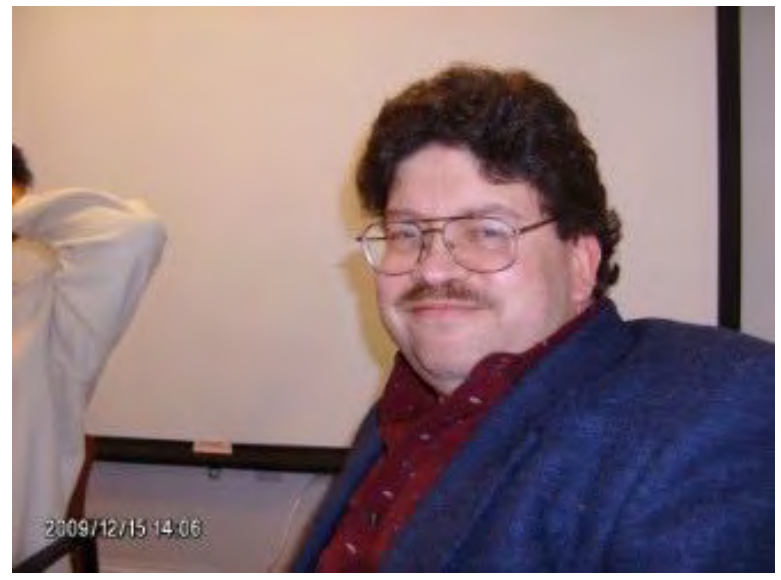

Photo courtesy of Nancy Zingrone

Even more than his erudite and punctilious (e.g., Alvarado, 1984) historical contributions and articles contributing to make the study of out-of-body experiences scientifically respectable, I mourn the passing of a warm and generous friend of many decades. I first met Carlos (and Nancy Zingrone, of course) in the mid-80s, when I attended an intense and extraordinary Summer Research Institute of the Foundation for the Research on the Nature of [Hu]Man (FRNM), which later became the Rhine Research Institute. Those were heady days, all of us drenched in sweat under the Durham sun and the lectures and discussions of all matters psi, not to mention participating in the odd psi experiment. In one, I learned first-hand the capricious nature of psi research, having had a clear and bizarre image during a ganzfeld session which I drew despite my reluctance to commit anything to paper. Alas, it was not the randomly-chosen target (that was my second choice). So, in a sense I did not score according to the pre-established rules, in another it was obvious to me that in some way the

1 Address correspondence to: Etzel Cardeña, Ph. D, Thorsen Professor, Department of Psychology, Center for Research on Consciousness and Anomalous Psychology (CERCAP), Lund University. Allhelgona kyrkogata 16a, Lund, 22100, Sweden, Etzel.Cardena@psy.lu.se 
image I later saw had affected my mentation earlier on. I got a poltergeist book from Richard Broughton as a reward for being the highest scorer in his PK Poink game, although I have not since showing any appreciable PK talent. John Palmer was another important faculty in the institute and has been a friend for decades. I also remember that Summer for some unforgettable performances at the American Dance Festival at Duke Universe, and for losing my bike-theft innocence (I have had various other bikes stolen since then).

I came back later to the FRNM as a faculty, not a student, and stayed with Carlos and Nancy once or twice, generosity being one of their cardinal traits. We collaborated later on two papers on OBEs (Cardeña \& Alvarado, 2014, Zingrone et al., 2010) and, when I was named Editor of the Journal of Parapsychology I did not hesitate for a second to ask Carlos to be the journal's book reviews editor. His vast network and ability to read various languages brought that section of the journal up to a new standard. Although usually gentle, Carlos was also courageous when the situation demanded it. At my forced departure as Editor of that journal, he was the first (out of many) members of the Editorial Board to resign from it and support the creation of a new journal (this one, in which a number of us are honoring him). I had asked him to be an Associate Editor of this journal as well, but alas his cancer took him from us way too early. The German poet Heinrich Heine wrote that if he were to meet again his deceased father, he would not wish to encounter him as a transfigured being, but wearing his old brown coat (Hofmann, 2021). Similarly, were I ever to meet Carlos again, I hope it will not be in some purified version of him, but sporting his whimsical smile and talking in his mellifluous boricua accent.

I will introduce now the other sections of this tribute to Carlos. Invariably the contributors expressed great affection for him in our related correspondence. First, the German historian Andreas Sommer describes the impact Carlos had in showing that at the inception of psychology and psychiatry as disciplines there was no "woo" (the pejorative term used by some to refer to psychical research and parapsychology) science and "real" science, but a plethora of foundational figures that drank from the same knowledge well. That Carlos carried this message through mainstream publications certainly helped the field immensely.

The following contribution, by the Australian Harvey Irwin, himself also someone of international stature in the study of parapsychology and Out-of-Body-Experiences (OBE), emphasizes the landmark contributions of Carlos (and Nancy Zingrone) to the study of the $O B E$, bringing it from the esoteric literature into mainstream psychology. Alfonso Martínez-Taboas, a Puerto Rican psychologist, describes the young Carlos as a charming and courageous young person burrowing his personal path intro para- 
psychology. The Italian Massimo Biondi focuses on the international scope and interest of Carlos to make parapsychology not a discipline purely of the USA and Northern Europe, but one that has to acknowledge and integrate the contributions and perspectives from other lands. The last two testimonials, by Wellington Zangari and Fatima Machado, and by Alexander Moreira-Almeida, show what a boon Carlos was for psi research in Brazil through his works and, as importantly, his personal and professional support for his colleagues.

These contributions are not intended to offer a longitudinal and comprehensive overview of Carlos's work. Fortunately, the Society for Psychical Research's encyclopedia has one entry that does just that: https://psi-encyclopedia.spr.ac.uk/articles/ carlos-s-alvarado\#Professional_Posts_and_\%20Honours).

Carlos, this issue of the Journal of Anomalous Experience and Cognition is dedicated to you.

\section{References}

Alvarado, C.S. (1984). Palladino or Paladino? On the spelling of Eusapia's surname, Journal of the Society for Psychical Research, 52, 315-316.

Cardeña, E. \& Alvarado, C. (2011). Altered consciousness from the Age of Enlightenment through mid $20^{\text {th }}$ century. In E. Cardeña, \& M. Winkelman (Eds.), Altering consciousness. Multidisciplinary perspectives. Volume I. History, culture, and the humanities (pp. 89-112). Praeger.

Cardeña, E., \& Alvarado, C. (2014). Anomalous self and identity experiences. In E. Cardeña, S. J., Lynn, \& S. Krippner (Eds.), Varieties of anomalous experience: Examining the scientific evidence. $2^{\text {nd }}$ ed. (pp. 175-212). American Psychological Association. Doi: 10.1037/14258-007

Duggan, M., \& Matlock, J. G. (2021). Carlos S. Alvarado. Psi Encyclopedia. https://psi-encyclopedia.spr.ac.uk/articles/carlos-s-alvarado\#Professional_Posts_and_\%20Honours.

Hofmann, M. (2021). Heine's heartmobile. New York Review of Books,63(12),

Zingrone, N., Alvarado, C., \& Cardeña, E. (2010). Out-of-body experiences and physical activity and posture: Survey responses from a survey conducted in Scotland. Journal of Nervous and Mental Diseases, 198, 163-165. Doi: 10.1097/nmd.0b013e3181cc0d6d 